Original Research Article

\title{
A cross-sectional study of drug prescription pattern in psoriasis patients attending dermatology and venereology department in a rural tertiary care teaching hospital
}

\author{
Sushil Kumar Varma, Shanta Das Sutradhar*
}

Department of Pharmacology, Mahatama Gandhi Institute of Medical Sciences, Sewagram, Wardha, Maharashtra, India

Received: 02 June 2017 Accepted: 27 June 2017

*Correspondence to: Dr. Shanta Das Sutradhar, Email: drshantasutradhar@ gmail.com

Copyright: (C) the author(s), publisher and licensee Medip Academy. This is an openaccess article distributed under the terms of the Creative Commons Attribution NonCommercial License, which permits unrestricted noncommercial use, distribution, and reproduction in any medium, provided the original work is properly cited.

\begin{abstract}
Background: Psoriasis is a chronic, inflammatory, multisystem disease which predominantly affects skin, joint, scalp and nail. Treatment strategies for psoriasis include topical therapy, systemic therapy and phototherapy (PT). Treatment usually depends on the severity, location and extent of lesion. Drug prescription studies are necessary for the recognition of areas for improvement and improving drug prescribing practices in hospitals. There are very few reports regarding drug prescription pattern in psoriasis patients. Hence we conducted this study.

Methods: This was a cross-sectional study conducted on 50 newly diagnosed psoriasis patients who attended Dermatology and Venereology outpatient department of a tertiary care hospital. The prescriptions from the patients were collected for the duration of 18 months and details of prescription were collected in case record forms. The assessment of disease severity was done by psoriasis area severity index (PASI) score.

Results: Majority of the patients (46\%) belonged to the age group of 41-55years. The mean age of the patients was $42.48 \pm 12.29$ years. Most of the patients with mild form of psoriasis were treated with topical therapy. Topical therapy included high potency steroids alone or in combination with salicylic acid and calcipotriol. Patients with more severe form of disease received combination of topical, systemic and phototherapy. Systemic therapy included oral Methotrexate and phototherapy was given as narrow band UVB (NBUVB). Further long term study is required to for proper assessment of prescription pattern in psoriasis patients. Conclusions: Most of the patients with psoriasis can be effectively treated with topical medications, and additional systemic and/or phototherapy may be required only for severe cases.
\end{abstract}

Keywords: Psoriasis, Phototherapy, PASI score, Systemic therapy, Topical therapy

\section{INTRODUCTION}

Drugs have an important role in the improvement of human health and promotion of well-being. However, drugs should be safe, efficacious and have to be used rationally to produce the desired effect. Because of underuse, overuse or misuse of drugs, often optimal benefits of drug therapy are often not achieved. ${ }^{1}$ Irrational use of drugs can lead to ineffective and unsafe treatment, exacerbation or prolongation of illness, distress and harm to the patient and higher costs. ${ }^{2}$ Without the knowledge on how drugs are being prescribed, it is difficult to understand the rational use of drugs. Drug prescription pattern can explain the profile, extent and quality of drug use. ${ }^{1}$

Psoriasis is a genetically determined immune mediated common dermatological disorder which affects skin, nails, and joints and also has various systemic associations. ${ }^{3}$ During the last few years, psoriasis therapy has been evolved rapidly and at present, newer and more effective medication and various combination regimens have become available. For patients presenting with mild psoriasis the recommended initial treatments are topical agents such as topical corticosteroids, emollients, coal tar, topical vitamin 
D3 analogues (calcipotriol) and topical retinoid. Moderate to severe psoriasis are required more intense treatment with phototherapy and with systemic agents. ${ }^{4}$ So, treatment of psoriasis has now become complicated due to the availability of various topical agents, systemic agents and phototherapy. ${ }^{5}$ The pattern of therapy depends upon the type, severity, and duration of the disease. ${ }^{6}$

Because of the availability of wide therapeutic options, the pattern of treatment may vary in different geographical regions and also in different medical establishments, depending upon the facilities and resources. There are very few reports and systematically analyzed data available in the Indian literature, regarding the pattern of drug use in psoriasis. Hence this study was conducted.

\section{METHODS}

\section{Study design}

The present study was a cross sectional study conducted to assess the drug prescription pattern in psoriasis patients attending Dermatology and Venereology Department in a Rural Tertiary Care Teaching Hospital of central India for a period of 18 months (from January 01, 2014 to June 30, 2015).

The patients were enrolled with prior written informed consent in English, Hindi and Marathi languages after fully explaining the study procedure to their satisfaction. Permission for collection of data from Dermatology and Venereology Department had been taken for conducting the study. Approval and clearance from the Institutional Ethics Committee was obtained before conducting the study.

\section{Sample size}

The present study was conducted on newly diagnosed psoriasis patients attending Dermatology and Venereology (D and V) OPD during the 18 months study period. During this study period, 50 newly diagnosed psoriasis patients attended the D and V OPD and all of them fulfilled the inclusion and exclusion criteria and were included in our study.

\section{Inclusion criteria}

- New cases of psoriasis patients attending Dermatology and Venereology OPD during the study period.

- Patients who gave their written informed consent for participation in the study.

\section{Exclusion criteria}

- Patients who were already under treatment for psoriasis.

- Drugs used for other reasons associated with these diseases.
- Drug induced psoriasis.

- Lack of consent for participation in the study.

\section{Study procedure}

After signing the consent form, relevant data were collected from the prescription of the patients, immediately following consultation. Information about general particulars of the patients and the drugs prescribed to patients were noted. Collected data are as follows:

- Particulars of the patients which included patient initials, age, sex, address of the patients, date of visit.

- Diagnosis of the patients.

- $\quad$ Psoriasis area severity index (PASI) score

- Drug details noted were as follows:

Name, dose and frequency, route, duration, total number of drugs.

The above data was recorded using a Case Record Form (CRF).

The severity of psoriatic lesions was assessed by measuring psoriasis area severity index (PASI) score. PASI score is the current gold standard for severity assessment of psoriasis. ${ }^{7}$ PASI quantifies extent and severity of skin involvement in different body regions as a score from 0 to $72 .{ }^{8}$ It is the measure of the average of the redness, thickness, and scaliness of the psoriatic lesions. ${ }^{7}$

\section{Statistical analysis}

Statistical analysis was done by using descriptive and inferential statistics using Chi- square test. The software used in the analysis was SPSS 17.0 version and Graph Pad Prism 5.0. $\mathrm{p}$-value $<0.05$ was considered as level of significance.

\section{RESULTS}

Table 1: Age and gender distribution $(n=50)$.

\begin{tabular}{|c|c|c|c|}
\hline \multirow{2}{*}{$\begin{array}{l}\text { Age } \\
\text { distribution }\end{array}$} & \multicolumn{3}{|l|}{ Gender (\%) } \\
\hline & Male & Female & Total \\
\hline $10-25$ & $1(2 \%)$ & $3(6 \%)$ & $4(8 \%)$ \\
\hline $26-40$ & $8(16 \%)$ & $6(12 \%)$ & $14(28 \%)$ \\
\hline $41-55$ & $12(24 \%)$ & $11(22 \%)$ & $23(46 \%)$ \\
\hline $56-70$ & $6(12 \%)$ & $3(6 \%)$ & $9(18 \%)$ \\
\hline Total & $27(54 \%)$ & $23(46 \%)$ & $50(100 \%)$ \\
\hline Mean \pm SD & $44.37 \pm 10.65$ & $40.26 \pm 13.89$ & $42.48 \pm 12.29$ \\
\hline «2-value & \multicolumn{3}{|c|}{$2.02, p=0.56, N S, p>0.05$} \\
\hline
\end{tabular}

$\mathrm{n}$-Number of patients, $\mathrm{k} 2$-value -Chi-square value, SD-Standard deviation, NS-Non-significant.

Table 1 shows that out of the 50 patients, 27 (54\%) were males and $23(46 \%)$ were females. The mean age in psoriasis patients was $42.48 \pm 12.29$ years and majority of 
the patients (46\%) were in the age group of between 41-55 years $(n=23)$.

Table 2: PASI scores of different types of psoriasis.

\begin{tabular}{|llll|}
\hline $\begin{array}{l}\text { Type of } \\
\text { psoriasis }\end{array}$ & MASI Scores & \\
\hline CPP & 1.3 & 32 & $9.33 \pm 8.22$ \\
\hline CP and SCLP & 4 & 16.2 & $9.08 \pm 6.28$ \\
\hline GP & 4.4 & 5.4 & $5.08 \pm 0.36$ \\
\hline PS & 21.5 & 21.50 & $21.50 \pm 0.00$ \\
\hline $\begin{array}{l}\text { CP and } \\
\text { PPLNT }\end{array}$ & 5.9 & 5.90 & $5.90 \pm 0.00$ \\
\hline Total & 1.30 & 32 & $8.97 \pm 7.63$ \\
\hline
\end{tabular}

CPP- Chronic plaque psoriasis, CP and SCLP- Chronic plaque with scalp psoriasis, GP- Guttate psoriasis, PS- Pustular psoriasis, $\mathrm{CP}$ and PPLNT- Chronic plaque with palmoplantar psoriasis.

Table 2 show that, in patients with chronic plaque psoriasis the mean PASI score was $9.33 \pm 8.22$. The mean PASI score was $5.08 \pm 0.36$ in guttate psoriasis, 21.50 in pustular psoriasis, and 5.90 in chronic plaque with palmoplantar psoriasis and $9.08 \pm 6.28$ chronic plaque with scalp psoriasis indicating most severe form of disease in pustular psoriasis. Out of all the psoriasis patients the mean PASI score was 8.97 \pm 7.63 .

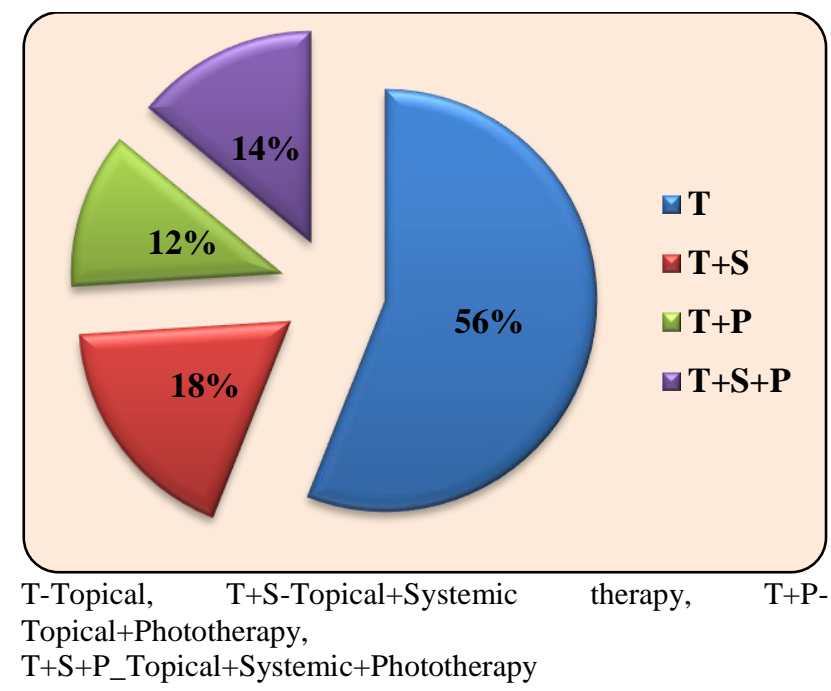

Figure 1: Prescription pattern of different of treatment modalities.

Figure 1 shows that out of 50 patients, 28 patients (56\%) were treated with topical therapy (T) alone, $18 \%$ of patients $(n=9)$ with combination of topical and systemic therapy $(\mathrm{T}+\mathrm{S}), 12 \%$ of patients $(\mathrm{n}=6)$ with combination of topical and phototherapy $(\mathrm{T}+\mathrm{P}) .14 \%$ of patients $(n=7)$ with combination of topical agents, systemic agents and phototherapy $(\mathrm{T}+\mathrm{S}+\mathrm{P})$.

Figure 2 shows that, topical therapy (T) was given in patients with PASI score $<6$ with mean PASI score of $4.28 \pm 1.13$. In patients with topical+systemic therapy $(T+S)$, the mean PASI score was $15.91 \pm 8.0$. In patients with topical+phototherapy $(\mathrm{T}+\mathrm{P})$, the mean PASI score as $6.66 \pm 0.73$. In patients with topical+ systemic+ phototherapy $(\mathrm{T}+\mathrm{S}+\mathrm{P})$ the mean PASI score was $20.51 \pm 5.85$.

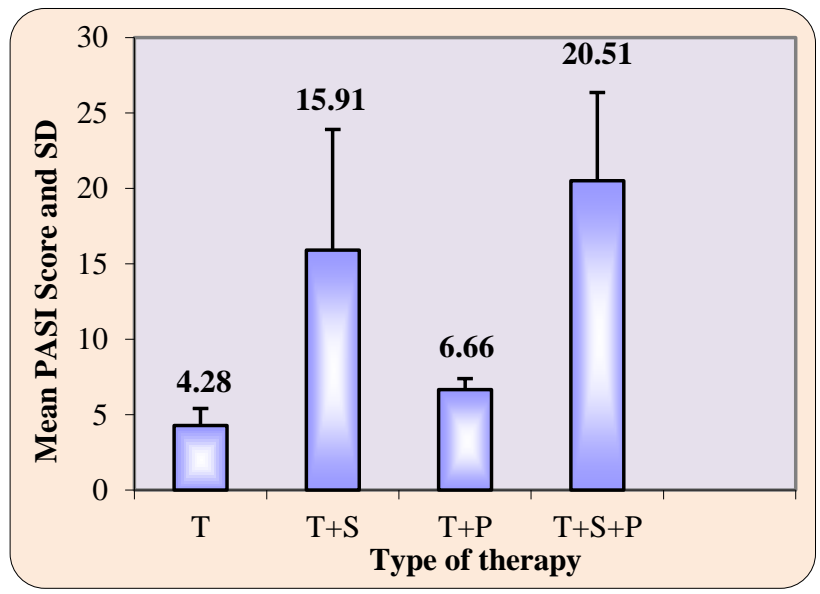

Figure 2: Different types of treatment modalities and PASI score.

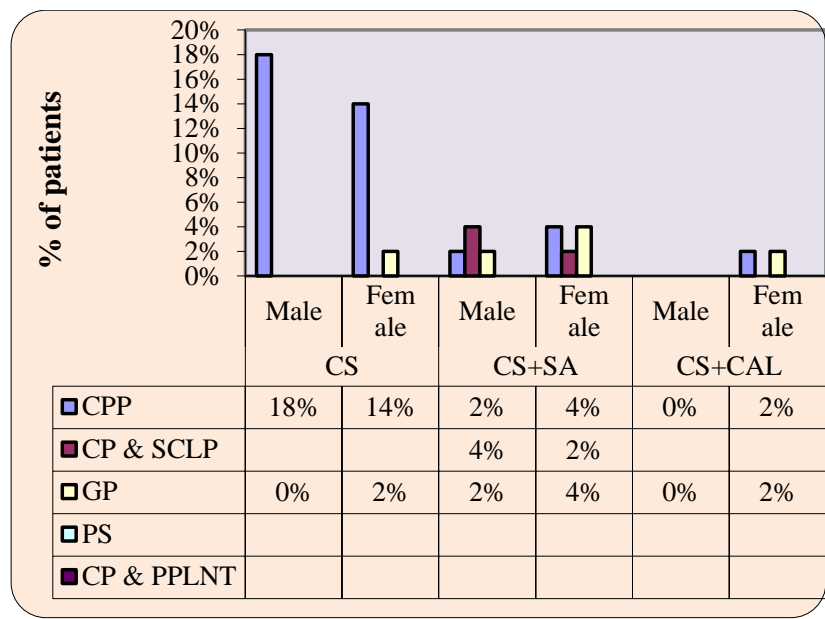

CS-Corticosteroid, CS+SA-Corticosteroid + Salicylic acid, CS+CAL-Corticosteroid + Calcipotriol, T-Topical therapy.

Figure 3: Different types of topical therapy.

Figure 3 shows that among topical therapy, corticosteroid (CS) alone was prescribed in 17 patients (34\%), in combination with salicylic acid (CS+SA) was prescribed in 9 patients $(18 \%)$ and in combination with calcipotriol was prescribed in 2 patients $(4 \%)$.

CS monotherapy was prescribed in $32 \%$ patients with CPP $(\mathrm{n}=16)$ and $2 \%$ patients with GP $(\mathrm{n}=1) ; \mathrm{CS}+\mathrm{SA}$ combination therapy was prescribed in $6 \%$ patients with CPP $(n=3), 6 \%$ patients with CP and SCLP $(n=3)$ and $6 \%$ patients with GP $(n=3)$; $C S+C A L$ combination therapy was prescribed in $2 \%$ patients with CPP $(n=1)$ and $2 \%$ patients with GP $(n=1)$. None of the patients with PS and CP and PPLNT received topical therapy alone. 


\section{DISCUSSION}

In the present study, the drug prescription pattern was assessed in 50 newly diagnosed psoriasis patients, who attended the Dermatology and Venereology OPD. All these 50 newly diagnosed psoriasis patients fulfilled the inclusion and exclusion criteria.

The mean age of the patients was $42.48 \pm 12.29$ years which was similar to that observed in other studies..$^{9-11}$ Majority of the study patients $(46 \%)$ were in the age group of between 41-55 years (n-23). Although psoriasis is considered to have a "dual peak" in age of onset, in our study we could not find "dual peak" in age of onset and instead we found that the incidence of psoriasis increases steadily with age until approximately the $6^{\text {th }}$ decade of life, with a more rapid increase in the rate of incidence in between age 41-55 followed by age 26-40. In a similar study, Megha $\mathrm{M}$ et al, also found steady increase in incidence of psoriasis until $7^{\text {th }}$ decade with rapid increase in the rate of incidence until age $30-35 .^{12}$

In present study, higher prevalence of psoriasis was observed in males as compared to females, though there was no significant difference in the mean age in male and female patients. Similar prevalence was observed in various other studies. ${ }^{9-11,13}$

The patient with pustular psoriasis had the most severe form of disease and guttate psoriasis had the mildest form of disease. This severity pattern of psoriasis was in accordance with literature which stated that, pustular psoriasis is a very serious and life threatening condition. ${ }^{14,15}$ The mean baseline PASI score in all psoriasis patients was $8.97 \pm 7.63$. Similarly, Mehta $S$ et al, also observed mean PASI score of $9.04 \pm 8.90$ in their study. ${ }^{16}$

In this study, the therapy for psoriasis mainly involved topical application of various medications alone or in combination with systemic and phototherapy in selected cases.

In the present study, topical therapy alone was considered in all patients with the baseline PASI score<6. It was similar to the finding observed by Raghunandan $\mathrm{R}$ et al, where topical therapy alone was prescribed in patients with PASI score $<4 .{ }^{6}$

Combination of topical and systemic therapy was prescribed in patients with more severe psoriasis with baseline PASI score $>8$. Similarly, Sabiqa Haider et al, in his study used Methotrexate in patients with PASI $>10 .{ }^{10}$

Combination of topical + phototherapy was used in patients of moderate psoriasis with baseline PASI score of $>6$ and combination of topical + systemic + phototherapy was used only for severe cases of psoriasis with extensive lesions with baseline PASI score $>10$.
Similar treatment pattern was shown in the study conducted by Raghunandan et al. ${ }^{6}$

Majority of the patients in our study, were treated with topical medications which included corticosteroids (CS), salicylic acid (SA), calcipotriol and coal tar, either as monotherapy or in combination of two or more drugs, in the form of creams, ointments and lotions. CSs used were Clobetasol (n-24), Halobetasol (n-2) and Betamethasone (n-2). Similarly, in a study conducted by Raghunandan $\mathrm{R}$ et al, majority of patients $(78.51 \%)$ were treated with topical therapy. ${ }^{6}$ One study conducted in UK reported that $94 \%$ of patients were treated with topical therapy alone. ${ }^{17}$

In our study, CS was prescribed for maximum up to 4 weeks. SA and CAL were advised to continue for the rest of the treatment period. Most of the topical corticosteroids were very potent and according to National Institute for Health and Care Excellence (NICE) guideline, these should not be used continuously at any site for longer than 4 weeks. Continuous application of very potent psoriasis may cause irreversible skin atrophy and striae, unstable psoriasis and systemic side effects. Therefore, non steroidbased topical therapy should be considered to maintain psoriasis disease control during rest of the period. ${ }^{18}$ This might be the reason for 4 weeks duration of CS therapy in our study.

$\mathrm{T}+\mathrm{S}$ was prescribed in $18 \%$ of patients with baseline PASI score $>8$. Systemic therapy included oral Methotrexate and oral acitretin. Systemic therapy with oral Methotrexate 7.5 mg once weekly, supplemented with folic acid was used in 6 patients (12\%). The weekly dose of Methotrexate (7.5 $\mathrm{mg}$ ) was divided into 3 doses of $2.5 \mathrm{mg}$ at 12 hourly intervals, and was continued for 12 weeks. Folic acid was given $5 \mathrm{mg}$ once daily for 6 days a week for 12 weeks in all of these patients. In patients who received Methotrexate, investigations including $\mathrm{Hb} \%$, TLC, platelet count, RBS, ESR, LFT, RFT were done at baseline and at the end of 12 weeks. Raghunandan et al, reported systemic therapy with Methotrexate in patients with PASI $>7$ and similar dose pattern of Methotrexate was used. ${ }^{6}$

In present study, topical agents given along with systemic therapy included CS alone or in combination with SA and CAL. Methotrexate starts acting within one month and maximum effects develop within 2 months. On the other hand, topical corticosteroid rapidly decreases acute inflammation. For this reason, combination of Methotrexate and topical Corticosteroid is beneficial in psoriasis. $^{19}$

$\mathrm{T}+\mathrm{P}$ was used in 6 patients of moderate psoriasis with baseline PASI score of $>6$. Phototherapy was given as narrow band UVB irradiation (NBUVB) twice weekly for 12 weeks. The initial dose was calculated based on minimal erythema dose (MED) given for 2 minutes, and the titration of dose and duration of irradiation was based upon treatment response as assessed in subsequent visits. MED is referred to as the lowest UVB dose producing 
defined perceptible erythema at the test site. CS+SA combination was used as topical therapy in all these 6 patients. Topical adjunctive therapy can be considered with phototherapy in psoriatic lesions present at difficultto-treat or covered sites. ${ }^{18}$

In our study, $\mathrm{T}+\mathrm{S}+\mathrm{P}$ was used only for very severe cases of psoriasis with baseline PASI score >10. British Association of Dermatologists (BAD) treatment guidelines for psoriasis also recommend using of very potent therapies including phototherapy, systemic drugs such as Methotrexate, acitretin, for severe cases of psoriasis. ${ }^{20}$ Combined use of UVB with systemic therapy is helpful in patients with severe psoriasis. ${ }^{21}$ In our study, topical therapy including CS in combination with salicylic acid was used along with systemic and phototherapy. Similar pattern of therapy was reported by Raghunandan et al, in their study, where combination of topical, systemic, phototherapy was given in patients with PASI $>8{ }^{6}$

\section{Funding: No funding sources}

Conflict of interest: None declared

Ethical approval: The study was approved by the Institutional Ethics Committee

\section{REFERENCES}

1. Shalini S, Ravichandran V, Mohanty BK, Dhanaraj SK, Saraswathi R. Drug utilization studies: an overview. Inter $\mathbf{J}$ Pharmaceut Sci Nanotechnol. 2010;3(1):803-10.

2. Desalegn AA. Assessment of drug use pattern using WHO prescribing indicators at Hawassa University teaching and referral hospital, South Ethiopia: a crosssectional study. BMC Health Services Research. 2013;13:170.

3. Dogra S, Yadav S. Psoriasis in India: prevalence and pattern. Indian J Dermatol Venereol Leprol. 2010;76(6):595-601.

4. Vijayan M, Shini VK, Emmanuel J, Dharmaratnam AD. Prevalence, clinical profile and prescribing pattern of psoriasis in a tertiary care referral hospital. International Journal of Pharmacy and Technology. 2010 December;2(4):1241-52.

5. Pearce DJ, Spencer L, Hu J, Balkrishnan R, Fleischer AB Jr, Feldman SR. Class 1 topical corticosteroid use by psoriasis patients in an academic practice. J Dermatolog Treat. 2004 July;15(4):235-8.

6. Raghunandan R, Pundarikaksha HP, Gopal MG. Pattern of drug use in the management of psoriasis in a tertiary care hospital: a prospective study. Int $\mathrm{J}$ Basic Clin Pharmacol. 2014;3(4):611-8.

7. Feldman SR, Krueger GG. Assessment: domains and instruments. Psoriasis assessment tools in clinical trials. Ann Rheum Dis. 2005;64(2).
8. Louden BA, Pearce DJ, Lang W, Feldman SR. A simplified psoriasis area severity index (SPASI) for rating psoriasis severity in clinic patients. Dermatology Online Journal. 2004;10(2):7.

9. Icen M, Crowson CS, McEvoy MT, Dann FJ, Gabriel SE, Kremers HM. Trends in incidence of adult-onset psoriasis over three decades: a population-based study. Journal of the American Academy of Dermatology. 2009 Mar 31;60(3):394-401.

10. Haider S, Wahid Z, Najam-us-Saher, Riaz F. Efficacy of Methotrexate in patients with plaque type psoriasis. Pak J Med Sci. 2014;30(5):1050-3.

11. Ejaz A, Raza N, Iftikhar N, Iftikhar A, Farooq M. Presentation of early onset psoriasis in comparison with late onset psoriasis: A clinical study from Pakistan. Indian J Dermatol Venereol Leprol. 2009;75:36-40.

12. Tollefson MM, Crowson CS, Kremers HM. Incidence of psoriasis in children: a population-based study. $\mathrm{J}$ Am Acad Dermatol. 2010 Jun; 62(6):979-87.

13. Chiriac A, Solovan C, Chiriac AE, Foia L, Brzezinski P. A case-control study of epidemiological importance risk of family history of psoriasis. Our Dermatol Online. 2014;5(1):90-1.

14. Traub M, Marshall K. Psoriasis-pathophysiology, conventional and alternative approaches to treatment. Altern Med Rev. 2007 Dec;12(4):319-30.

15. Peters BP, Weissman FG, Mark. Gill. Pathophysiology and treatment of psoriasis. Am J Health-Syst Pharm. April 2000;57.

16. Mehta S, Singal A, Singh N, Bhattacharya SN. A study of clinicohistopathological correlation in patients of psoriasis and psoriasiform dermatitis. Indian $\mathbf{J}$ Dermatol Venereol Leprol. 2009;75:100.

17. Gillard SE, Finlay AY. Current management of psoriasis in the United Kingdom: patterns of prescribing and resource use in primary care. Int. Nov 2005;59(11):1260-7.

18. NICE clinical guideline 153.Psoriasis: The assessment and management of psoriasis. October 2012. Available at: http://www.nice.org.uk/ guidance/cg153/resources/guidance-psoriasis-pdf

19. Kozub P, Simaljakova M. Systemic therapy of psoriasis: Methotrexate; Bratisl Lek Listy. 2011;112(7):390-4.

20. Smith CH, Anstey AV, Barker JN, Burden AD, Chalmers RJ, Chandler DA, et al. British Association of Dermatologists' guidelines for biologic interventions for psoriasis 2009. British Journal of Dermatology. 2009 Nov 1;161(5):987-1019.

21. Van de Kerkhof PC. Therapeutic strategies: rotational therapy and combinations. van de Kerkhof PC. Clin Exp Dermatol. 2001 Jun;26(4):356-61.

Cite this article as: Varma SK, Sutradhar SD. A cross-sectional study of drug prescription pattern in psoriasis patients attending dermatology and venereology department in a rural tertiary care teaching hospital. Int J Basic Clin Pharmacol 2017;6:1987-91. 